Rakenteiden Mekaniikka (Journal of Structural Mechanics)

Vol. 52, No. 4, 2019, pp. 244-250

http://rakenteidenmekaniikka.journal.fi/index

https://doi.org/10.23998/rm.76405

(C) 2019 The Authors

Open access under license CC BY 4.0

\title{
Suitability of laminated steel-copper structure for high-pressure hydraulic manifolds
}

\author{
Lauri Siivonen ${ }^{1}$, Miika Paloniitty, Matti Linjama, Antti Hynnä and Sirpa Launis
}

Summary. Vacuum brazed steel-copper laminate could be used in high-pressure hydraulic manifolds in order to reduce size, weight and allow use of complex designs. The durability of such material is unknown. Samples were manufactured and static and dynamic tests were conducted. Results showed reduced material performance due to heat treatment. A hydraulic test manifold was manufactured and a long-term pressure load test was conducted. The material showed surprisingly good durability and pressure hull did not break in tests. A microscopic study was performed and only solidified copper in the corners had micro cracks after 10 million test cycles.

Keywords: hydraulic manifolds, vacuum brazing, steel-copper structure

Received 7 November 2018. Accepted 26 November 2019. Published online 31 December 2019.

\section{Introduction}

Steel has been used for hydraulic high-pressure (20-35 MPa) valve manifolds due to good characteristics in both use and in machining. Typical manifold sizes range between some centimetres to over a meter-sized blocks. The technology, design methods and machining is well known and proven to work. However, downside of the traditional approach is size and weight and since conventional machining methods set limitations on manifold design. Manufacturing process may become time-consuming and expensive if special shapes or component installation angles are required. Typical manifolds are cubic-shaped, and drillings are made perpendicular from each face. The use of different kinds of plugs may also be mandatory in order to fill the assistive drill holes.

Additive manufacturing (AM) is one of the most discussed methods to manufacture smaller parts with more flexible design [1]. Typical methods include metal jetting, binder jetting, photopolymer vat, material extrusion, powder bed fusion (PBF), directed energy

${ }^{1}$ Corresponding author: lauri.siivonen@tamlink.fi 
deposition (DED) and sheet lamination. PBF and DED methods are proven to work with metals [2]. Several examples can be found where reported weight and size savings of hydraulic manifold is considerable [3] and [4]. The main limitations for using AM are cost of equipment and base materials, speed of manufacturing process and need for surface treatment in some applications. In addition, the maximum size of the printed object is limited and compliance of 3D-printed manifold for hydraulic use is not well known. Durability of printed material has been studied in general [5] but not with loads typical for hydraulic systems. A similar technology as AM is vacuum brazed laminated structures, which have been used in low-pressure applications such as heat exchangers with good success [6]. The technology has been trialed in hydraulics at least twice in [7] and [8]. The aim of this study is to study the limitations and characteristics of laminated structures for use in hydraulic manifolds in general.

\section{Manufacturing of laminated steel-copper material}

A hybrid material formed by vacuum brazing from conventional $2 \mathrm{~mm}$ cold-rolled HC420LA low alloy steel sheets and thin copper layers is of the essence in this study.

The metal sheets were cut with industrial laser and copper coating of $6 \mu \mathrm{m}$ was applied with electrolysis. At first, a solid block was vacuum brazed (approx. $1100^{\circ} \mathrm{C}, 3$ hours), cut into pieces and a lathe was used for creating a suitable shape. The target was $10 \mathrm{~mm}$ diameter for test samples. The surface was finished by grinding, as polishing did not work for the material. It seems that copper starts to wear off before steel when polished. During polishing, it was notices that some of the pieces had some $0.5-1.0 \mathrm{~mm}$ deviation in axial direction. In practice, this material does not seem to endure conventional manufacturing methods as well as was hoped.

One test sample has 35 brazed copper-steel connections in the middle part with 10 $\mathrm{mm}$ diameter. This means maximum of $210 \mu \mathrm{m}$ of copper and likely less.

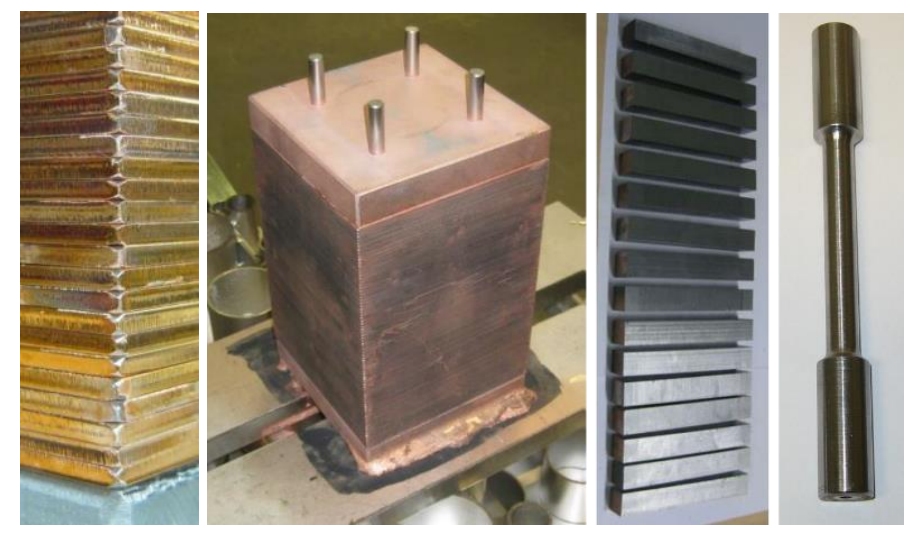

Figure 1. Rounded corners prior to brazing (left), vacuum brazed test manifold (middle), manifold pieces (middle) and test sample (right). 
Table 1. Tensile and yield strength measurement results.

\begin{tabular}{ccc}
\hline Sample & Tensile strength $\mathrm{R}_{\mathrm{m}}[\mathrm{MPa}]$ & Yield strength $\mathrm{R}_{\mathrm{eH}}[\mathrm{MPa}]$ \\
\hline 1 & 374 & 254 \\
2 & 346 & 252 \\
3 & 355 & 248 \\
\hline
\end{tabular}

\section{Tensile and yield strength measurement}

Three samples were tested for tensile and yield strength. Median tensile strength was 355 MPa with maximum deviation of $19 \mathrm{MPa}$. Median yield strength was $252 \mathrm{MPa}$ with maximum deviation of $4 \mathrm{MPa}$. All results are shown in Table 1 . The yield strength of the selected steel has originally been $420 \mathrm{MPa}$ and so it has been reduced to approximately $250 \mathrm{MPa}$.

An example of a test is shown in Figure 2. As can be seen in the measurement, there is relatively much yield before the sample breaks. The displacement is longer than theoretical maximum amount of copper and the tension is much higher than what would be expected from copper. The structure could not be polished due to practical reasons so comparison against known materials is more difficult as surface finishing has impact on fatigue [9]. Figure 3 shows ruptured surfaces of all three samples.

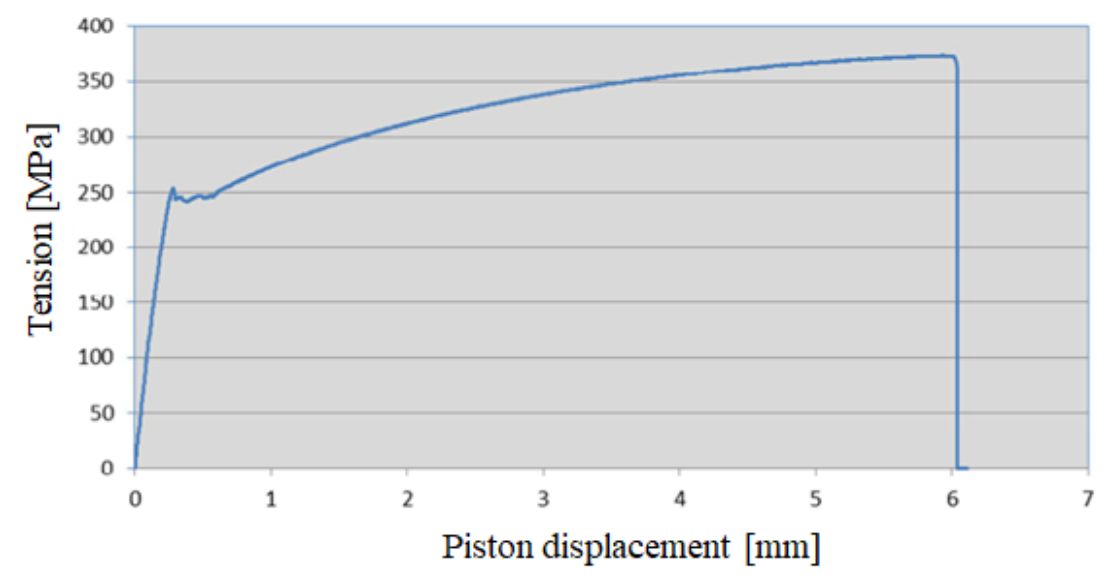

Figure 2. Tension test result with sample 1. 

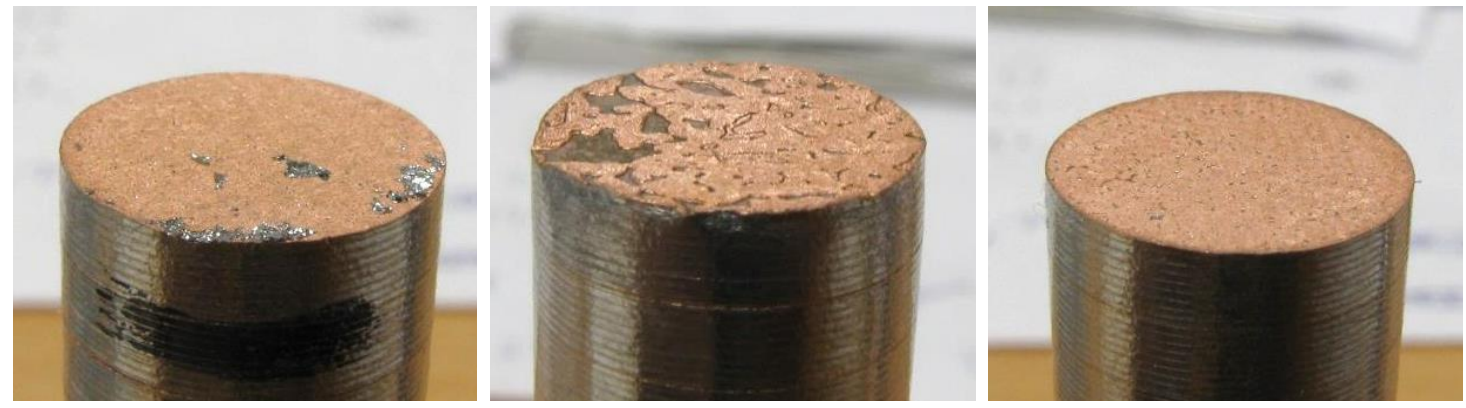

Figure 3. Images from three tested samples 1-3 (left to right).

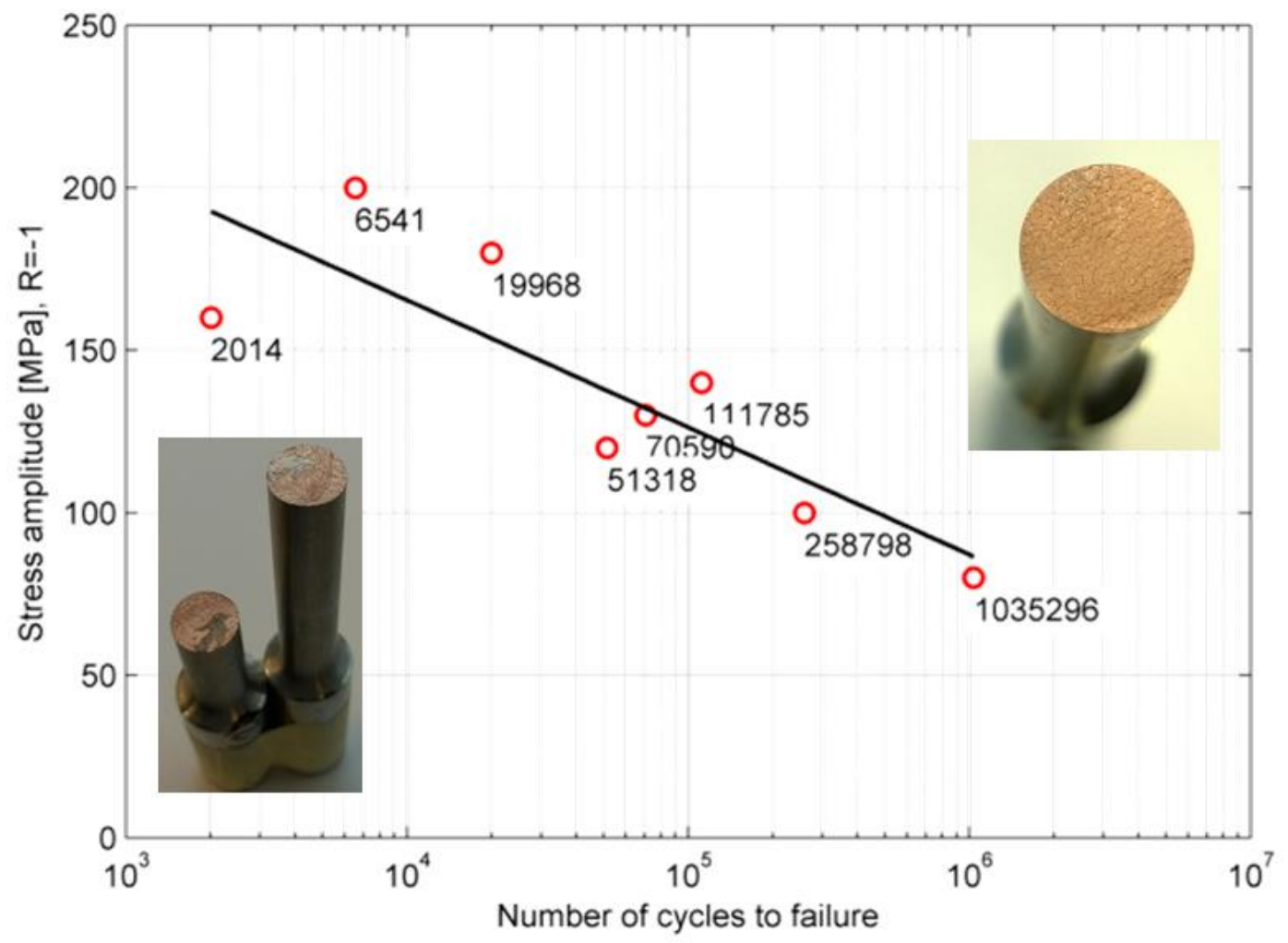

Figure 4. S/N curve for vacuum brazed steel-copper material.

\section{Fatigue test}

A series of fatigue tests were conducted in order to define the $\mathrm{S} / \mathrm{N}$ curve for the vacuumbrazed laminate material. Mean tension was selected to be zero in the tests $(R=-1)$. The tests were started from $200 \mathrm{MPa}$ load level after the static tests showed yield strength of approximately $250 \mathrm{MPa}$. The first test was promising with 6500 repeats completed before rupture. When load level was decreased down to $160 \mathrm{MPa}$, there was a worrying result of 2000 repeats. The rupture surface of this specimen seemed slightly different, as the copper had teared differently. The tests with smaller loads showed some deviation but not such 
a big difference as the $160 \mathrm{MPa}$ level. The tests were stopped when load level was relatively low, one million cycles was surpassed, and trend showed no sign of saturating.

Figure 4 shows the $\mathrm{S} / \mathrm{N}$ curve and two samples with ruptured surfaces from $160 \mathrm{MPa}$ and the last test. All samples failed from copper-steel connection point. The trend line is shown but may not represent the absolute truth, as there was some deviation in the measurements.

\section{Pressure load endurance test}

The static and dynamic tests showed decreased performance for the material and therefore a pressure load test was conducted in order to validate whether the effect is similar in aimed use of hydraulic manifolds. In practice, this means manufacturing a test manifold with pressure and an indication chamber to indicate whether the pressure hull cracks.
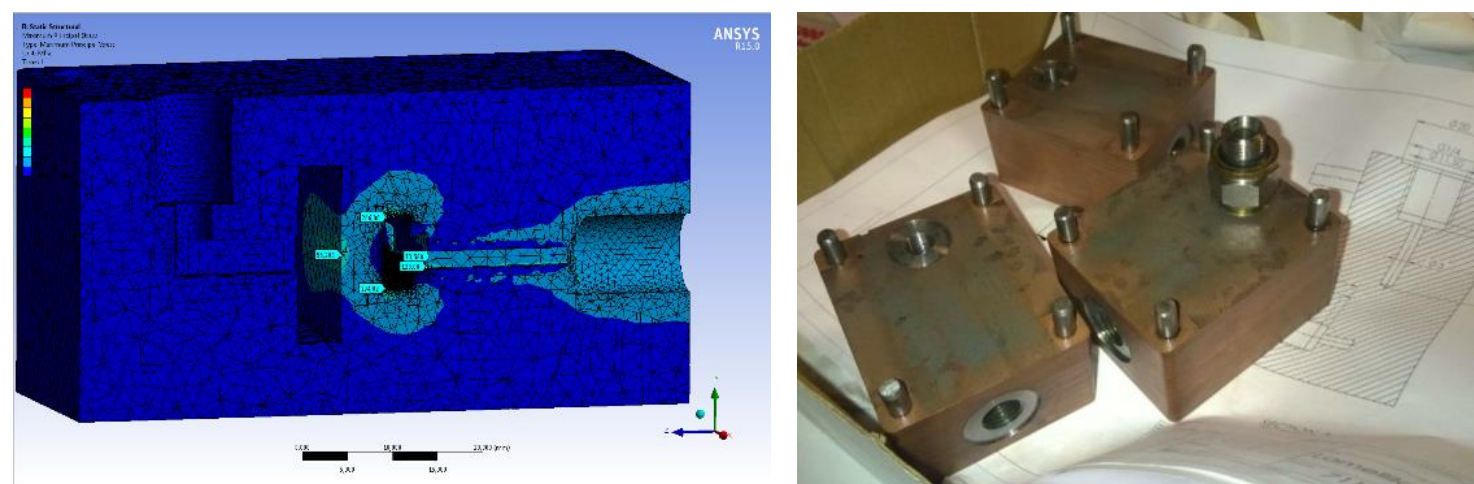

Figure 5. FEM calculation result and vacuum-brazed steel-copper test manifolds.

\section{FEM analysis and manifold design}

Based on the tension tests, a test manifold was designed so that it could potentially break after a certain number of pressure load cycles. FEM calculation was used (see Figure 5, left) but some of the parameters needed to be estimated due to lack of information. A copper rounding of $0.3 \mathrm{~mm}$ was used in calculations. $30 \mathrm{MPa}$ load cycle was planned and this led to $194 \mathrm{MPa}$ load on copper edge. Tension amplitude is 50\% from maximum tension and with $97 \mathrm{MPa}$ amplitude the lifetime was estimated to be 550000 cycles at worst based on the S/N curve (Figure 4). The hydraulic manifold was manufactured from same materials and same method as the previous manifold that was used to make samples for static and dynamic tension tests.

\section{Hydraulic manifold and pressure test analysis}

The manifold was tested with $30 \mathrm{MPa}$ square wave pressure load. The results were very promising from material perspective as the calculated potential breaking point was passed significantly. Test was ended after 10 million cycles, and the manifold was split into pieces and a micro-fracture study was conducted. 
Further analysis showed that cavity corners had copper rounding from vacuum brazing process (see Figure 6) as estimated in FEM study but the shape is not exactly round. The copper had fractures but steel-copper structure was intact in studied samples. Microscopic imaging also shows that steel plate cuttings are not straight. It is difficult to estimate how long this material would have lasted in pressure tests based on these results.

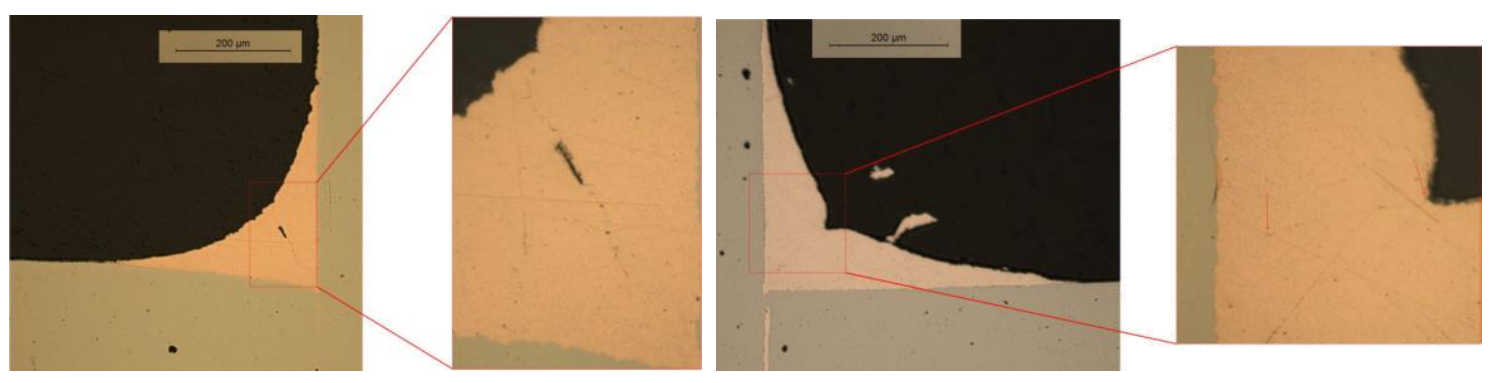

Figure 6. Microstructural images of the long-term test manifold.

\section{Conclusions}

The study showed that vacuum brazed steel-copper structure has lower yield strength than solid steel but considerably higher than copper. The material has limitations with high stresses and that conventional design methods do not apply for this structure. A manifold was successfully tested with high loads in realistic environment but the manifold did not break as was estimated. The results suggest that the material could be used in highpressure hydraulics as manifold material when certain limitations are taken into account. Main advantages of this manufacturing approach are low manufacturing costs and possibility to create complex 3D-structures without supports. Longer pressure tests and effect of fluid flow erosion on fatigue should be studied further in future.

\section{References}

[1] I. Gibson, D. Rosen and B. Stucker. Additive Manufacturing Technologies - 3D Printing, Rapid Prototyping, and Direct Manufacturing. Springer, ISBN 978-14939-2113-3, 2015 (2nd edition). DOI 10.1007/978-1-4939-2113-3

[2] Anon. What is Additive Manufacturing? https://www.ge.com/additive/additivemanufacturing (visited 7.11.2018)

[3] Anon. Integrated smart Actuator - High dynamic performance and compact design for mobile robotic hydraulic applications. Moog Inc., Mobium/PDF/Rev. A, October 2017, CDL51965-en.

[4] E. Komi and P. Kokkonen. Design approaches for additive manufactured components, with a focus on selective laser melting. Journal of Structural Mechanics, 50 (3), 279-282, 2017. https://doi.org/10.23998/rm.64915

[5] W.E. Frazier. Metal Additive Manufacturing: A Review. Journal of Materials Engineering and Performance, 23 (6), 1917-1928, 2014. https://doi.org/10.1007/s11665-014-0958-z 
[6] Anon. Vacuum Brazing. https://www.loval.fi/vacuum-brazing.html (visited 7.11.2018)

[7] R. Lasaar and A. Stoll. New Innovative Components for Energy Efficient Working Hydraulics in Mobile Machines. Proceedings of $7^{\text {th }}$ International Fluid Power Conference, Aachen, 2010.

[8] M. Paloniitty, M. Karvonen, M. Linjama and T. Tiainen. Laminated Manifold for Digital Hydraulics - Principles, Challenges and Benefits. Proceedings of the Fifth Workshop on Digital Fluid Power, October 24-25, 2012, Tampere, Finland.

[9] H.E. Boyer. Atlas of Fatigue Curves. ASM International, 1986. ISBN 0-87170214-2.

[10] M. Makkonen. Teknologiset tekijät teräksen väsymisessä (in Finnish). Journal of Structural Mechanics, 50 (1), 25-40, 2017. https://doi.org/10.23998/rm.63497

\section{Lauri Siivonen}

Tuotekehitys Oy Tamlink

Hermiankatu 6, P.O.Box 140, 33721, Tampere, Finland

lauri.siivonen@tamlink.fi

Miika Paloniitty, Matti Linjama, Antti Hynnä

Tampere University

Korkeakoulunkatu 6, FI-33720 Tampere, Finland

miika.paloniitty@tuni.fi,matti.linjama@tuni.fi, antti.hynna@tuni.fi

Sirpa Launis

Sandvik Mining and Rock Technology

Pihtisulunkatu 9, P.O. Box 100, 33311 Tampere, Finland

sirpa.launis@sandvik.com 